\title{
Teratogen-induced alterations in microRNA-34, microRNA-125b and microRNA-155 expression: correlation with embryonic p53 genotype and limb phenotype
}

Keren Gueta ${ }^{1}$, Natali Molotski ${ }^{2}$, Natalie Gerchikov ${ }^{1}$, Eyal Mor ${ }^{1}$, Shoshana Savion ${ }^{1}$, Amos Fein ${ }^{1}$, Vladimir Toder ${ }^{1}$, Noam Shomron ${ }^{1}$, Arkady Torchinsky ${ }^{1 *}$

\begin{abstract}
Background: In a large number of studies, members of the microRNA (miRNA)-34 family such as miRNA-34a, miRNA-34b, miRNA-34c, as well as miRNA-125b and miRNA-155, have been shown to be regulators of apoptosis. The ability of these miRNAs to perform this function is mainly attributed to their ability to interact with the p53 tumor suppressor, which is a powerful regulator of the teratologic susceptibility of embryos. We chose to explore whether miRNA-34a/b/c, miRNA-125b and miRNA-155 may play a role in teratogenesis by using $\mathrm{p} 53^{+/-}$pregnant mice treated with cyclophosphamide (CP) as a model. We evaluated how CP-induced alterations in the expression of these miRNAs in the embryonic limbs correlate with embryonic p53 genotype and CP-induced limb phenotypes.
\end{abstract}

Results: The limbs of p53 positive embryos were more sensitive to CP-induced teratogenic insult than the limbs of p53 negative embryos. The hindlimbs were more severely affected than the forelimbs. Robust miRNA-34a

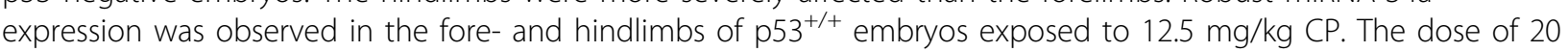
$\mathrm{mg} / \mathrm{kg}$ CP induced almost a two-fold increase in the level of miRNA-34a expression as compared to that exhibited

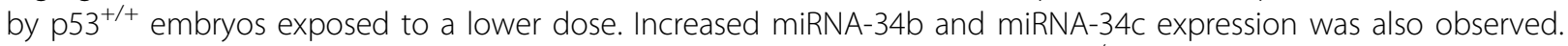
Of note, this dose activated miRNA-34a and miRNA-34c in the forelimbs of $\mathrm{p} 53^{-/-}$embryos. When embryos were exposed to $40 \mathrm{mg} / \mathrm{kg} \mathrm{CP}$, the expression pattern of the miRNA-34a/b/c was identical to that registered in the limbs of embryos exposed to $20 \mathrm{mg} / \mathrm{kg}$ CP. However, this dose suppressed miRNA-125b and miRNA-155 expression in the fore- and hindlimbs of $\mathrm{p} 53^{+/+}$embryos.

Conclusion: This study demonstrates that teratogen-induced limb dysmorphogenesis may be associated with alterations in miRNA-34, miRNA-125b and miRNA-155 expression. It also suggests for the first time that p53-independent mechanisms exist contributing to teratogen-induced activation of miRNA-34a and miRNA-34c. At the same time, teratogen-induced suppression of miRNA-125b and miRNA-155 expression may be p53 dependent. The analysis of correlations between the expression pattern of the tested miRNAs and CP induced limb phenotypes implies that miRNAs regulating apoptosis may differ from each other with respect to their functional role in teratogenesis: some miRNAs act to protect embryos, whereas other miRNAs boost a teratogen-induced process of maldevelopment to induce embryonic death.

\footnotetext{
* Correspondence: arkadyt@post.tau.ac.il

'Department of Cell and Developmental Biology, Sackler School of Medicine,

Tel Aviv University, Ramat Aviv, Tel Aviv, 69978, Israel
} 


\section{Background}

Mature microRNAs (miRNAs) are non-coding RNAs composed of about 22-nucleotide, that attenuate gene activity posttranscriptionally by inhibiting effective mRNA translation of target genes. Silencing takes place through sequence-specific base pairing between the miR and its target mRNAs [1,2]. By now, hundreds of miRNAs have been detected [3] and some miRNAs have been shown to be essential for normal embryonic development, controlling developmental events such as neurogenesis, angiogenesis, and the formation of limbs, heart and muscles $[4,5]$. In parallel, studies in invertebrates and various types of cultured cells revealed the ability of some miRNAs to regulate cell proliferation and apoptosis [6,7]. These observations have formulated a basis to suggest that miRNAs may play an important role in cancer formation, acting both as oncogenes and tumor suppressors [8]. Remarkably, these observations also suggest that miRNAs may act as regulators of embryos' susceptibility to developmental toxicants (teratogens). Indeed, apoptosis and cell proliferations are critically important processes of normal embryogenesis [9]. Teratological studies have revealed that the appearance of teratogen-induced structural anomalies is often preceded by excessive apoptosis in embryonic structures that are destined to be malformed $[10,11]$. At the same time, teratogen-induced apoptosis is also often registered in embryonic structures that appear normal at birth $[10,11]$. This demonstrates that the embryo is able to compensate for teratogen-induced cell death and, hence, teratologic susceptibility of embryos depends not only on the mechanisms regulating apoptosis but also on mechanisms regulating cell proliferation.

Recently, a number of studies have provided compelling evidence that members of the miRNA-34 family (hereafter abbreviated as miRNA-34) such as miRNA-34a, miRNA$34 \mathrm{~b}$ and miRNA-34c are direct transcription targets of the tumor suppressor protein $\mathrm{p} 53$, having the potential to regulate both apoptosis and cell proliferation [12]. The role of p53 as a regulator of teratological susceptibility of embryos has been demonstrated in studies with diverse teratogens such as benzo(a)pyrene [13,14], 2-chloro-2-deoxyadenosine [14], 4-hydroperoxycyclophosphamide [15], cyclophosphamide [16], ionizing radiation $[17,18]$ and diabetes [19]. Quite a few genes have been demonstrated as mediators of p53- induced apoptosis and cell arrest [20,21], but those acting in teratogen-exposed embryos remain largely undefined. Therefore, our question was whether miRNA-34 may be among targets engaged by p53 to regulate teratologic susceptibility of embryos.

Two other miRNAs, miRNA-125b and miRNA-155 also seemed to be good candidates for the role of teratologic regulators. Specifically, our and others study with cyclophosphamide $(\mathrm{CP})$ have revealed that excessive apoptosis is a major event in the pathogenesis of CP-induced process of maldevelopment [10,22]. p53 acts to intensify both CP-induced apoptosis and suppression of cell proliferation [16]. It also mediates CP -induced activation of caspase 3 and suppression of the transcription factor NF-kB DNA binding [16]. Furthermore, our recent work has implied that $\mathrm{CP}$-induced suppression of NF-kB signaling may be linked to CP-induced apoptosis and suppression of cell proliferation [23]. In turn, miRNA-155 has been shown to regulate apoptosis and suggested to target caspases 3 and NF-kB signaling $[24,25]$. MiRNA-125b has been suggested to control the expression of the tumor necrosis factor alpha (TNF $\alpha)$ [26], a cytokine, acting as a powerful activator of NF-kB [27]. Notably, our studies have provided evidence suggesting that TNF $\alpha$ may determine sensitivity of mice to CP-induced teratogenic insult [28].

Given the potential involvement of miRNA-34, miRNA-125b and miRNA-155 in the mechanisms regulating teratologic susceptibility of embryos, we chose to explore whether $\mathrm{CP}$ alters the expression of the miRNAs in the embryonic limbs and how the alterations correlate with the embryonic p53 genotype and CP-induced limb phenotypes. We used CP-treated p53 heterozygous mice as a model and the fore- and hindlimbs of p53 knockout and p53 positive embryos as target embryonic structures.

\section{Results}

\section{Reproductive performance of CP-treated mice}

In females injected with the highest dose of $\mathrm{CP}$ $(40 \mathrm{mg} / \mathrm{kg}$ ), the level of postimplantation death of embryos exceeded 26\% (Table 1). This was a significant increase when compared to that of females exposed to lower doses of $\mathrm{CP}$ and controls. In these females a trend to the departure from the Mendelian 25\%:50\%:25\% genotype ratio ( $\approx 29 \%: 60 \%: 11 \%)$ due to the death of $\mathrm{p} 53^{-1-}$ embryos was also registered. In mice exposed to lower doses of $\mathrm{CP}$ these indices did not differ significantly from those in controls (Table 1).

\section{Teratogenic response to $\mathrm{CP}$}

As expected, the forelimbs and hindlimbs exhibited differential sensitivity to $\mathrm{CP}$-induced teratogenic stimuli. Indeed, practically all fetuses of mice exposed to $40 \mathrm{mg} / \mathrm{kg}$ had digit anomalies of the fore- and hindlimbs (Table 2). At the same time, limb reduction anomalies of the hindlimbs but not of the forelimbs were registered in these fetuses. In females exposed to $20 \mathrm{mg} / \mathrm{kg}$, the proportion of embryos having digit anomalies of the forelimbs was significantly lower than that of embryos exhibiting digit anomalies of the hindlimbs. Finally, $\approx 30 \%$ of embryos exposed to $12.5 \mathrm{mg} / \mathrm{kg}$ CP had digit 
Table 1 Reproductive performance of $\mathrm{p53}^{+/-}$females treated with cyclophosphamide (CP) and tested on day 16 of pregnancy.

\begin{tabular}{|c|c|c|c|c|}
\hline \multirow[b]{2}{*}{ Indices } & \multicolumn{4}{|c|}{ Groups of females } \\
\hline & Control & $\mathrm{CP}(12.5 \mathrm{mg} / \mathrm{kg})$ & $\mathrm{CP}(20 \mathrm{mg} / \mathrm{kg})$ & $\mathrm{CP}(40 \mathrm{mg} / \mathrm{kg})$ \\
\hline Number of pregnant females & 8 & 10 & 14 & 10 \\
\hline Implantation sites/litter & $66 / 8.3$ & $84 / 8.4$ & $106 / 7.6$ & $83 / 8.3$ \\
\hline $\begin{array}{l}\text { Percent of resorptions } \\
\text { (arcsine, mean } \pm \mathrm{SE} \text { ) }\end{array}$ & $\begin{array}{c}6.1 \\
(16.2 \pm 3.4)^{a}\end{array}$ & $\begin{array}{c}4.8 \\
(15.4 \pm 2.5)^{\mathrm{a}} \\
\end{array}$ & $\begin{array}{c}13.2 \\
(23.5 \pm 3.6)^{\mathrm{a}} \\
\end{array}$ & $\begin{array}{c}26.5 \\
(32.0 \pm 2.0)^{b} \\
\end{array}$ \\
\hline \multicolumn{5}{|l|}{ Number of live fetuses } \\
\hline Total & 62 & 80 & 92 & 61 \\
\hline $\mathrm{p} 53^{+/+}$ & $18(29 \%)$ & $14(17.5 \%)$ & $16(17.4 \%)$ & $18(29.5 \%)$ \\
\hline $\mathrm{p} 53^{+/-}$ & $27(43.6 \%)$ & $46(57.5 \%)$ & $48(52.2 \%)$ & $36(59 \%)$ \\
\hline $\mathrm{p} 53^{-1-}$ & $17(27.4 \%)$ & $20(25 \%)$ & $28(30.4 \%)$ & $7(11.5 \%)$ \\
\hline
\end{tabular}

Superscripts denote results of statistical analysis of values within a row. Values not sharing common superscripts are significantly different (the GT-2 test, $\mathrm{p}<$ 0.05).

anomalies of the hindlimbs but only single fetuses had malformed forelimbs (Table 2).

\section{Effects of p53 embryonic genotype}

In females exposed to $20 \mathrm{mg} / \mathrm{kg}, \approx 38 \%$ of p53 positive embryos had digit anomalies of the forelimbs and nearly $100 \%$ had digit anomalies of the hindlimbs (Table 3). At the same time, no p53 negative embryos with malformed forelimbs were detected and $\approx 14 \%$ of the embryos had digit anomalies of the hindlimbs. Limb reduction anomalies were also observed only in the hindlimbs of p53 positive embryos (Table 3 ). The same relationship between teratologic limb phenotypes and p53 embryonic genotype was registered when mice were exposed to other doses of CP. Thus, the limbs of p53 negative embryos of females exposed to $12.5 \mathrm{mg} / \mathrm{kg} \mathrm{CP}$ were normal, whereas $10 \%$ and $\approx 40 \%$ of p53 positive embryos had digit anomalies of the forelimbs and hindlimbs, respectively. When mice were exposed to 40 $\mathrm{mg} / \mathrm{kg} \mathrm{CP}$, digit anomalies of the forelimbs were observed in all p53 positive embryos and in $\approx 71 \%$ of p53 negative embryos. Limb reduction anomalies of the hindlimbs were also observed in $70 \%$ of p53 negative embryos and all p53 positive embryos. Thus, these results demonstrate that the limbs of $\mathrm{p} 53$ positive embryos are more sensitive to CP than the limbs of p53 knockout embryos, with differential teratologic sensitivity of the fore- and hindlimbs being independent on p53 embryonic genotype.

\section{Influence of CP on miRNA-34a expression}

$\mathrm{CP}$ at a dose of $12.5 \mathrm{mg} / \mathrm{kg}$ induced robust miRNA-34a expression in the fore- and hindlimbs of $\mathrm{p}^{2} 3^{+/+}$but not in the limbs of $\mathrm{p} 53^{-1-}$ embryos (Figure 1). No statistically significant differences in miRNA-34a levels registered in the fore- and hindlimbs were observed. When females were treated with $20 \mathrm{mg} / \mathrm{kg} \mathrm{CP}, \mathrm{p} 53^{+/+}$embryos exhibited statistically insignificant but almost two-fold increase in the level of miRNA-34a expression as compared to that registered in the embryos exposed to the

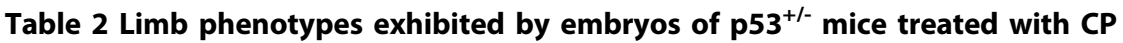

\begin{tabular}{|c|c|c|c|c|}
\hline Doses of cyclophosphamide & & $12.5 \mathrm{mg} / \mathrm{kg}$ & $\mathrm{CP} 20 \mathrm{mg} / \mathrm{kg}$ & $\mathrm{CP} 40 \mathrm{mg} / \mathrm{kg}$ \\
\hline Number of tested embryos & & 80 & 92 & 61 \\
\hline Type of anomalies & & \multicolumn{3}{|c|}{ Fetuses with malformed $\operatorname{limbs}^{\S}$} \\
\hline \multirow{4}{*}{$\begin{array}{c}\text { Digit anomalies1arcsine, } \\
\text { mean } \pm \text { SE }\end{array}$} & Forelimbs & $6(7.5 \%)$ & $24(26.1 \%)$ & $59(96.7 \%)$ \\
\hline & & $17.7 \pm 3.5^{\mathrm{a}}$ & $32.4 \pm 3.1^{\mathrm{b}}$ & $73.0 \pm 0.5^{c}$ \\
\hline & Hindlimbs & $23(28.8 \%)$ & $66(71.7 \%)$ & $61(100 \%)$ \\
\hline & & $32.5 \pm 3.5^{a *}$ & $55.9 \pm 3.8^{b_{*}}$ & $78.9 \pm 0.3^{c}$ \\
\hline \multirow{4}{*}{$\begin{array}{l}\text { Limb reduction anomalies, } \\
\text { arcsine, mean } \pm \text { SE }\end{array}$} & Forelimbs & 0 & 0 & 0 \\
\hline & & $9.9 \pm 0.3$ & $10.7 \pm 0.4$ & $11.0 \pm 0.3$ \\
\hline & Hindlimbs & 0 & $24(26.1 \%)$ & $61(100 \%)$ \\
\hline & & $9.9 \pm 0.3^{\mathrm{a}}$ & $32.4 \pm 3.1^{b_{*}}$ & $78.9 \pm 0.3^{\mathrm{C}_{*}}$ \\
\hline
\end{tabular}

'Digit anomalies that were registered included syndactyly, ectrodactyly, adactyly. Limb reduction anomalies included amelia, apodia and hemimelia.

${ }^{5}$ No fetuses with digit and limb anomalies were found in litters of control mice. Superscripts denote results of statistical analysis of values within a row. Values not sharing common superscripts are significantly different (the GT-2 test, $\mathrm{p}<0.05$ ).

*Differences between the fore- and hindlimbs are statistically significant (Student's t-test, $p<0.05$ ). 
Table 3 Effects of p53 on CP-induced limb phenotype (dose of $20 \mathrm{mg} / \mathrm{kg}$ )

\begin{tabular}{|c|c|c|c|c|}
\hline \multirow[t]{2}{*}{ Tested embryonic structure } & \multirow[t]{2}{*}{ p53 genotype } & \multirow[t]{2}{*}{ Number of tested embryos } & \multicolumn{2}{|c|}{ Number of embryos exhibiting: } \\
\hline & & & Digit anomalies & Limb reduction anomalies \\
\hline \multirow[t]{2}{*}{ Forelimbs } & $+/+$ and $+/-$ & 64 & $24(37.5 \%)$ & 0 \\
\hline & $-/-$ & 28 & $0^{*}$ & 0 \\
\hline \multirow[t]{2}{*}{ Hindlimbs } & $+/+$ and $+/-$ & 64 & $62(96.9 \%)$ & $24(37.5 \%)$ \\
\hline & $-/-$ & 28 & $4(14.3 \%)^{*}$ & $0^{*}$ \\
\hline
\end{tabular}

Differences between p53 positive and p53 negative embryos are statistically significant (the Fisher exact test, $p<0.05$ ).

lower dose of CP. Remarkably, this dose of CP also induced 2-fold increase in miRNA-34a expression in the forelimbs of $\mathrm{p} 53^{-1-}$ embryos. In the limbs of embryos exposed to $40 \mathrm{mg} / \mathrm{kg} \mathrm{CP}$ the expression pattern of the $\mathrm{miR}$ was identical to that registered in the limbs of embryos exposed to $20 \mathrm{mg} / \mathrm{kg}$ CP (Figure 1). No differences in the levels of miRNA-34a expression were observed in fore- and hindlimbs of control $\mathrm{p}^{5} 3^{+/+}$and $\mathrm{p} 53^{-/-}$embryos (data not presented).

\section{Influence of CP on miRNA-34b and miRNA-34c expression} The expression of miRNA-34b and miRNA-34c was not altered in the limbs of embryos exposed to $12.5 \mathrm{mg} / \mathrm{kg}$ CP (Figure 1). When females were treated with $20 \mathrm{mg} / \mathrm{kg}$ $\mathrm{CP}$, the level of miRNA-34b and miRNA-34c expression in the limbs of $\mathrm{p} 53^{+/+}$embryos were statistically significantly higher than that in the limbs of controls but obviously lower than miRNA-34a levels. Besides, this dose of CP resulted in a statistically significant increase in miRNA-34c expression in the forelimbs of $\mathrm{p} 53^{-1-}$ embryos. Finally, the expression pattern of these miRNAs in the limbs of embryos exposed to $40 \mathrm{mg} / \mathrm{kg} \mathrm{CP}$ did not differ from that registered in the limbs of embryos exposed to $20 \mathrm{mg} / \mathrm{kg} \mathrm{CP}$ (Figure 1). No differences in the levels of miRNA-34b and miRNA-34c expression were observed in fore- and hindlimbs of control $\mathrm{p}_{53^{+/+}}$and $\mathrm{p} 53^{-/-}$embryos (data not presented).

\section{Influence of CP on miRNA-155 and miRNA-125b expression}

The only observed effect on miRNA-155 and miRNA$125 \mathrm{~b}$ expression was in the limbs of $\mathrm{p} 53^{+/+}$embryos exposed to $40 \mathrm{mg} / \mathrm{kg}$ CP. A 1.7 - 2-fold decrease in the expression level of these miRNAs was registered (Figure 1). No differences in the levels of miRNA-155 and miRNA-125b expression were observed in fore- and hindlimbs of control p $53^{+/+}$and $\mathrm{p} 53^{-/-}$embryos (data not presented).

\section{Discussion}

The objectives of this study were formulated as follows: 1) to evaluate whether $\mathrm{CP}$-induced teratogenic insult alters the expression of several miRNAs (miRNA-34, miRNA$125 \mathrm{~b}$ and miRNA-155) in mouse embryonic limbs and to

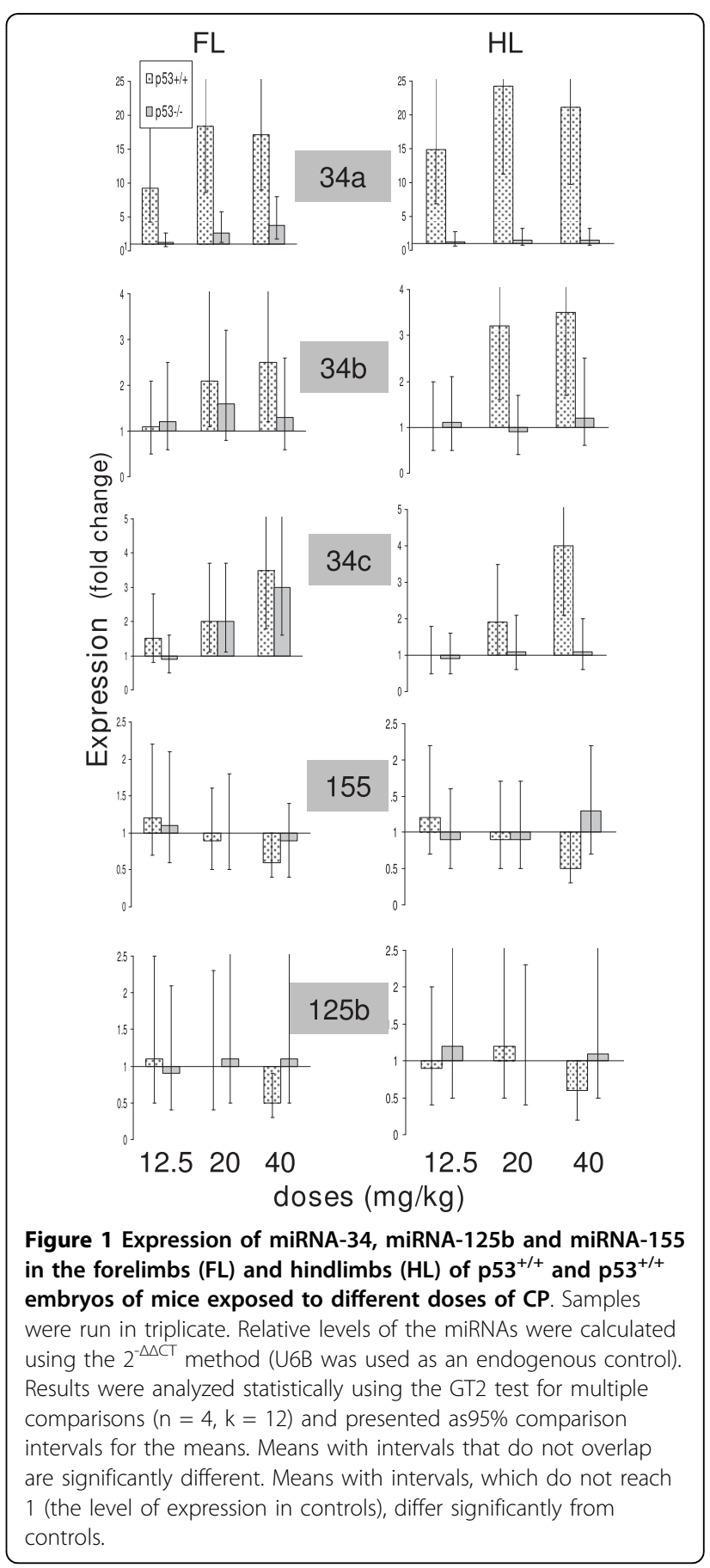


what extent these alterations are mediated by $\mathrm{p} 53$; and 2 ) to estimate how $\mathrm{CP}$-induced alterations in the expression of the miRNAs correlates with CP-induced limb phenotypes. We observed that the expression of all tested miRNA-34 family members was elevated in the limbs of

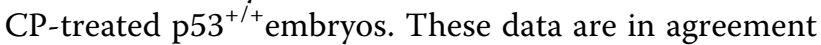
with those obtained in earlier studies that addressed the effect of p53 on miRNA-34 expression in mice exposed to ionizing radiation $[29,30]$. Interestingly, miRNA-34a was identified as being strongly regulated by p 53 regardless of cell type or stress [31], and in our study, the magnitude of CP-induced activation of miRNA-34a in the limbs of $\mathrm{p}^{+/++}$embryos was also significantly higher than that of miRNA-34b and miRNA-34c. Yet, in the studies cited above and studies addressing the expression of miRNA34a only [32], DNA-damaging stress-induced activation of the miRNA-34 family was found to be highly p53 dependent. By contrast, in our work, miRNA-34a and miRNA$34 \mathrm{c}$ were found to be activated not only in the limbs of $\mathrm{CP}$-treated $\mathrm{p}^{2} 3^{+/+}$embryos but also in the forelimbs of CP-treated p53 knockout embryos. As the expression level of miRNA-34a was significantly higher in the former, this observation does not question the role of p53 as a bona fide mediator of CP -induced activation of miRNA-34a. Interestingly, however, miRNA-34c expression was practically identical in the limbs of CP-treated $\mathrm{p} 53^{+/+}$and $\mathrm{p} 53^{-/-}$ embryos. Altogether, our data demonstrate for the first time that in some embryonic tissues p53-independent mechanisms may exist, contributing to teratogen-induced activation of miRNA-34a and miRNA-34c. (After the manuscript was submitted for publication, evidence appeared demonstrating p53-independent activation of miRNA-34a in primary human TIG3 fibroblasts during oncogene-induced senescence [33]).

Whereas the levels of miRNA-34 increased in CP-treated embryos, miRNA-125b and miRNA-155 levels clearly tended to decrease in the limbs of $\mathrm{p} 53^{+/+}$embryos exposed to $40 \mathrm{mg} / \mathrm{kg} \mathrm{CP}$. We have not encountered any publications addressing the expression of miRNA-155 in teratogen-treated embryos. As to miRNA-125b, its expression was found to be decreased in embryos of female rats treated with such a teratogen as retinoic acid [34]. Two other teratogens, ionizing radiation and camptothecin [35], have been shown to suppress miRNA-125b expression in zebrafish embryos [36]. Our results concur with the above observations and, in parallel, for the first time, demonstrate that teratogeninduced suppression of miRNA-125b and miRNA-155 may be p53 dependent.

The analysis of studies addressing the biological activities of miRNA-34, miRNA-125b and miRNA-155 strongly suggests that all tested miRNAs may be involved in the mechanism of determining the response of the embryo to CP-induced teratogenic stimuli. Indeed, apoptosis and suppression of cell proliferation are key intermediate cellular events in $\mathrm{CP}$ teratogenesis $[16,22,28]$, and our studies indicate that p53 acts to intensify these events [16]. The miRNA-34 is activated by p53 being able to mediate p53-induced proapoptotic and antiproliferative effects. Besides, recent observations suggest the ability of miRNA-34a to indirectly increase p53 activity [37]. Finally, we observed miRNA-34a and miRNA-34c activation in the forelimbs of CP-treated p53 knockout embryos. In this context, it is noteworthy that p53-independent mechanisms of miRNA-34a-induced apoptosis were suggested [38]. It also supposes that miRNA-34a may act in cooperation with miRNA-34c, which is predicted to have the same seed regions and mRNA targets [31]. A recent study reinforces this proposition: cells exposed to a DNA double-strand break agent (doxorubicin: DOX) demonstrated that only simultaneous inhibition or forced expression of miRNA-34a and miRNA-34c resulted in the inhibition or induction of DOX-mediated apoptosis [39]. These observations seemingly suggest the possibility of miRNA-34a and miRNA-34c mediating CP-induced apoptosis in the forelimbs of $\mathrm{p} 53^{-1-}$ embryos. On the other hand, unlike miRNA-34 ability to act in concert with p53, miRNA$125 \mathrm{~b}$ and miRNA-155 seem to have the potential to function as inhibitors of CP-induced p53-mediated apoptosis. Indeed, it has been shown that miRNA-155 suppresses the expression of the tumor protein 53-induced nuclear protein 1, which induces apoptosis and cell arrest in several cell lines [40]. Furthermore, there exist data implying that miRNA-155 can be a blocker of caspase 3 activation $[24,25]$, which in turn is activated by teratogenic doses of $\mathrm{CP}$ in a p53-dependent fashion [16]. As to miRNA-125b, it was recently suggested to be a bona fide negative regulator of p53 in zebrafish and humans [36]. Finally, as miRNA-155 and miRNA-125b exhibited similar expression patterns, an intriguing question was whether $\mathrm{CP}$ induced suppression of these miRNAs can intensify p53mediated apoptosis employing shared targets of these miRNAs. To address this question, we employed three independent miR target prediction databases: TatgetScan [41] TargetRank [42] and PITA [43] and then crossed these data to find high-confidence putative targets. As a result, five genes, such as SOX11, KCNA1, E2F2, ETS1 and MAP3K10, were predicted as common targets for miRNA-125b and miRNA-155. Two of them have the potential to intensify p53-mediated apoptosis. The first one is ETS1, which is suggested to be required for p53 transcriptional activity [44]. The second, MAP3K10, was shown to induce P53-mediated apoptosis following phosphorylation [45].

In the light of the above data, the activation of miRNA-34 and suppression of miRNA-125b and miRNA-155 in the limbs of CP-treated embryos may be 
suggested as pathogenetic events in CP-induced apoptosis and, hence, CP-induced limb dysmorphogenesis. Yet, if we analyze how the changes in the expression profile of the miRNAs correlate with the severity of the $\mathrm{CP}$-induced teratologic phenotype, the above suggestion is compromised. Indeed, in the limbs of embryos exposed to 20 and $40 \mathrm{mg} / \mathrm{kg} \mathrm{CP}$, the expression profile of these miRNAs was identical although the higher dose affected limb development much stronger. Also, at all dose levels, the hindlimbs of the embryos were more severely affected than the forelimbs. Yet, the levels of miRNA-34, miRNA-125b and miRNA-155 expression were found to be practically identical in the hindlimbs and the forelimbs of p53-positive embryos. In addition, an elevated expression of miRNA-34a and miRNA-34c was detected only in less teratologically sensitive forelimbs of p53 negative embryos. Together, these findings scarcely allow suggesting that these miRNAs mediate $\mathrm{CP}$-induced limb dysmorphogenesis. If it is the case, what is a possible explanation of this discrepancy?

A plausible explanation may be found if we bear in mind the concept proclaiming that the main function of miRNAs is to confer robustness to developmental programs [46-48]. Within this concept, the main function of miRNAs positively regulating apoptosis in the embryo may be formulated as preventing the birth of malformed offspring. These miRNAs may perform this function by either mediating an "adaptive apoptosis" which will contribute to the renewal of teratogen-targeted cell populations by promoting the removal of injured cells or activating teratogen-induced apoptosis in order to kill severely malformed embryos. If this is the case, a model may be proposed in which the activation of some proapoptotic miRNAs may represent an adaptive response to teratogenic apoptotic stimuli, whereas other proapoptotic miRNAs are activated and/or antiapoptotic miRNAs are suppressed to strengthen teratogen-induced apoptosis. This model does not contradict results obtained from teratological studies implying that proapoptotic signaling may be indispensable for embryo protection again teratogenic stress [11]. It is also in agreement with the suggestion that miRNAs are ideal candidates for the safeguarding of organisms during environmental stresses $[48,49]$. Finally, within the context of this model, some of the results can be partially explained. Indeed, only miRNA-34a was activated in $\mathrm{p} 53^{+/+}$embryos exposed to $12.5 \mathrm{mg} / \mathrm{kg} \mathrm{CP}$. Of note, this miRNA is suggested to be the most stress-sensitive member of the miRNA-34 family [31], whereas the dose of $12.5 \mathrm{mg} / \mathrm{kg}$ is a threshold teratogenic dose for these embryos. A further increase in miRNA-34a expression and an elevated expression of miRNA-34b and miRNA-34c were detected in $\mathrm{p} 53^{+/+}$ embryos exposed to $20 \mathrm{mg} / \mathrm{kg}$, a dose, to which a part of embryos are still able to resist. At the same time, the expression pattern of the miRNA-34 did not change in embryos exposed to a dose of $40 \mathrm{mg} / \mathrm{kg}$ severely affecting all embryos. Instead, the expression of miRNA-125b and miRNA-155 having the potential to negatively regulate the p53-mediated proapoptotic signaling was suppressed. Remarkably, the observation that the expression pattern of all tested miRNAs was identical in the forelimbs and hindlimbs of CP-treated $\mathrm{p} 53^{+/+}$embryos does not contradict the proposed model.

\section{Conclusion}

This study demonstrates that teratogen-induced limb dysmorphogenesis may be associated with alterations in miRNA-34, miRNA-125b and miRNA-155 expression. It also suggests for the first time that in some embryonic tissues p53-independent mechanisms may exist, contributing to teratogen-induced activation of miRNA-34a and miRNA-34c, whereas teratogen-induced suppression of miRNA-125b and miRNA-155 expression may be p53 dependent. Finally, the analysis of correlations between the expression pattern of the tested miRNAs and CP-induced limb phenotypes allows us to hypothesize that miRNAs regulating apoptosis may differ from each other with respect to their functional role in teratogenesis. Some miRNAs may act to protect embryos, whereas other miRNAs may boost a teratogen-induced process of maldevelopment thus inducing embryonic death. This hypothesis should be taken into account in further studies addressing the role of miRNAs in teratogenesis.

\section{Methods}

\section{Animals and CP treatment}

Breeding pairs of p53 knockout mice bearing a mutation deleting $40 \%$ of the p53- coding region and completely blocking production of p53 protein [50] were received as a gift from Prof. Moshe Oren (Weizmann Institute of Science, Israel), and now a colony of these mice is being maintained in Tel Aviv University Animal Facility on a $14 \mathrm{~h}$ light: $10 \mathrm{~h}$ darkness cycle by crossing $\mathrm{p} 53^{+/-}$ females with $\mathrm{p} 53^{-/-}$males. To obtain pregnancies, 3 -month-old $\mathrm{p} 53^{+/-}$females were caged with $\mathrm{p} 53^{+/-}$ males for $3 \mathrm{~h}$, from 0700 to $1000 \mathrm{~h}$ (darkness), and the presence of a vaginal plug $(1100 \mathrm{~h})$ was designated as day 1 of gestation. CP (Sigma) was injected intraperitoneally at $1000 \mathrm{~h}$ of day 12 of gestation at $12.5,20$ or 40 $\mathrm{mg} / \mathrm{kg} \mathrm{CP}$ (in $0.5 \mathrm{ml}$ saline $/ 20 \mathrm{~g}$ body weight). Pregnant females injected with saline $(0.5 \mathrm{ml} / 20 \mathrm{~g}$ bodyweight) were used as a control throughout the study. Animal experiments were approved by the Ethics Committee for Animal Use of Tel Aviv University.

\section{Genotyping}

Genotyping of embryos was performed as described elsewhere [16]. Briefly, DNA was extracted from the amnion 
and PCR was performed using PCR mix (Promega), DNA, and 3 primers (Sigma): 5'-ACAGCGTGGTGGTACCTTAT-3', 5'-TATACTCAGAGCCGGCCT-3', and 5'-CTATCAGGACATAGCGTTGG-3' [50] under the following conditions: initial preheating at $948 \mathrm{C}$ for $3 \mathrm{~min}$ followed by 30 cycles of the following three steps: 1 ) denaturing $(948 \mathrm{C})$ for $30 \mathrm{~s}, 2)$ annealing $(558 \mathrm{C})$ for $30 \mathrm{~s}$, and 3) extension (72 8C) for $1 \mathrm{~min}$ followed by $3 \mathrm{~min}$ at $728 \mathrm{C}$. PCR products were diluted in a DNA-loading buffer and loaded on $1.2 \%$ agarose gel diluted in a TBE buffer with ethidium bromide (Sigma).

\section{Teratological testing}

The spectrum of external anomalies induced by $\mathrm{CP}$ in mice is very wide [51]. Our choice of the forelimbs and hindlimbs as targets was based on our and other studies demonstrating that these organs are extremely but differentially sensitive to the teratogen (the hindlimbs exhibit higher sensitivity) $[22,52,53]$. To evaluate the CP-induced limb teratologic phenotypes, females were sacrificed by cervical dislocation on day 16 of gestation, the uteri were removed and implantation sites, resorptions and live embryos were recorded. Live fetuses were fixed in Bouin's solution, and examined visually for structural anomalies such as adactyly, ectrodactyly, syndactyly (digit anomalies) as well as more severe limb reduction anomalies such as, apodia, hemimelia and amelia. As we previously showed, the response of $\mathrm{p} 53^{-1-}$ embryos to $\mathrm{CP}$-induced teratogenic stimuli strikingly differs from that demonstrated by $\mathrm{p} 53^{+/+}$and $\mathrm{p} 53^{+/-}$embryos, which, in turn, are equally sensitive to the teratogen [16]. Therefore, the results characterizing teratogenic response of $\mathrm{p} 53^{+/+}$and $\mathrm{p} 53^{+/-}$embryos were pooled.

\section{miRNA analysis}

Evaluation of the expression of miRNA-34, miRNA$125 \mathrm{~b}$ and miRNA-155 was performed in the fore- and hindlimbs of $\mathrm{p} 53^{+/+}$and $\mathrm{p} 53^{-/-}$embryos collected 24 hours after $\mathrm{CP}$ injection. The choice of this time point was based on our previous studies [16,23] that revealed that embryos tested 24 hours after CP treatment exhibited not only prominent apoptosis but also the highest levels of the expression of such proapoptotic molecules as caspases 3, 8 and 9, the strongest suppression of DNA-binding activity of an anti-apoptotic molecule, the transcription factor NF-kB, and the lowest levels of the expression of molecules acting in the classical NF- $k B$ signaling pathway such as IKK $\beta, \operatorname{IkB} \alpha, \mathrm{I}-\mathrm{kB} \beta$ and I-kBe. To obtain a tested sample, embryos collected from fivesix litters were pooled. The expression of the miRNAs was tested in four samples obtained for control and experimental groups.

\section{RNA extraction}

Extraction of miRNA-enriched total RNAs was performed using QIAGEN's RNeasy Plus Mini Kit (QUIAGENE, Hilden, Germany) following the manufacturer's protocol with slight modifications. Briefly, a tested embryonic structure was homogenized using RLT lysis buffer mixed with $\beta$-mercaptoethanol. The homogenate was transferred to a gDNA Eliminator spin column. Then, the lysate obtained was added with 1.5 volumes of $100 \%$ ethanol, transferred to a filter spin column and washed twice in order to increase RNA quality. Finally, RNA was eluted with nuclease-free water and the sample was evaluated for quality and quantity by ND-1000 according to the manufacturer's V3.5 User's Manual for the NanoDrop ND-1000 Spectrophotometer (NanoDrop Technologies, Wilmington, DE).

\section{Quantitative Real-Time PCR}

In order to test the integrity of the small RNA fraction in our specimens prior to miRNA profiling, we performed quantitative analysis of a non-coding small RNA, U6 RNA as described below. Based on results obtained, it is reasonable to assume that miRNAs are intact and could be accurately quantified in the tested specimens. Real-Time PCR samples were prepared using a TaqMan PCR master mix and specific real-time primers for the tested miRNAs (ABI) according the manufacturer's protocol with slight modifications using $\mathrm{ABI}$ $7900 \mathrm{HT}$ fast real-time PCR system. Briefly, $7 \mu \mathrm{l}$ realtime mixture containing $0.5 \mu \mathrm{l}$ R product, $0.35 \mu \mathrm{l}$ realtime primer (including a probe, the forward and reverse primers) and $1 \times$ TaqMan Universal PCR Master Mix was prepared. The mixture was incubated in a 384-well plate at $95^{\circ} \mathrm{C}$ for $10 \mathrm{~min}$, followed by 40 cycles of $95^{\circ} \mathrm{C}$ for $15 \mathrm{~s}$ and $60^{\circ} \mathrm{C}$ for $1 \mathrm{~min}$. All reactions were run in triplicates. miRNA expression levels were calculated by using the ABI 7500 Real-Time PCR SDS 1.2 software (ABI). The $2^{-\triangle \Delta C T}$ method [54] was used to calculate relative expression of the tested miRNAs.

\section{Statistical analysis}

Statistical analysis of the teratological data was performed on a litter basis using the GT2-method for multiple comparisons [55]. For this, values characterizing the proportions of resorptions and malformed fetuses in each litter of each group were transformed to arsine values by FreemanTukey's method as described elsewhere [56] and the means and standard errors of these indices were calculated for each group. To look for an association across treatment groups, embryonic genotypes and teratologic phenotypes, the $\chi^{2}$ test was run as described [57]. GT2-method for multiple comparisons was used to analyze statistically 
data characterizing the expression of the miRNAs. The two-tailed level of significance of differences was equal to 0.05 for all tested parameters.

\section{Acknowledgements}

This work was supported by a grant 6234-1 from the Israel Ministry of Health to AT and grants from the Chief Scientist Office of the Ministry of Health, Israel (3-4876), the Kurz-Lion Foundation, The Ori Levi Foundation for Mitochondrial Research and Tel Aviv University, Faculty of Medicine, Schreiber Fellowship to NS.

\section{Author details}

'Department of Cell and Developmental Biology, Sackler School of Medicine, Tel Aviv University, Ramat Aviv, Tel Aviv, 69978, Israel. ${ }^{2}$ Department of Biological Chemistry, the Weizmann Institute of Science, Rehovot, Israel.

\section{Authors' contributions}

KG - performed miRNA analysis, participated in p53 genotyping and teratological testing; NM - guided and performed miRNA analysis; NG performed p53 genotyping and participated in miRNA analysis and teratological testing; EM - miRNA targets prediction and functional analysis; SS and AF- performed teratological testing and interpreted thereof, helped drafting the manuscript; NS - interpreted results of miRNA analysis and drafted the manuscript; $V T$ and AT - conceived the study, planned experiments and wrote the majority of the paper. All authors read and approved the final manuscript.

Received: 11 June 2009

Accepted: 21 February 2010 Published: 21 February 2010

\section{References}

1. Ambros V: The functions of animal microRNAs. Nature 2004, 431:350-355

2. Bartel DP: MicroRNAs: genomics, biogenesis, mechanism, and function. Cell 2004, 116:281-297.

3. Griffiths-Jones S: miRBase: the microRNA sequence database. Methods Mol Biol 2006, 342:129-138.

4. Bushati N, Cohen SM: microRNA functions. Annu Rev Cell Dev Biol 2007, 23:175-205.

5. Stefani G, Slack FJ: Small non-coding RNAs in animal development. Nat Rev Mol Cell Biol 2008, 9:219-230.

6. Carleton M, Cleary MA, Linsley PS: MicroRNAs and cell cycle regulation. Cell Cycle 2007, 6:2127-2132.

7. Jovanovic M, Hengartner MO: miRNAs and apoptosis: RNAs to die for. Oncogene 2006, 25:6176-6187.

8. Medina PP, Slack FJ: microRNAs and cancer: an overview. Cell Cycle 2008 , 7:2485-2492.

9. Vaux DL, Korsmeyer SJ: Cell death in development. Cell 1999, 96:245-254.

10. Mirkes PE: Cell death in normal and abnormal development. Congenit Anom(Kyoto) 2008, 48:7-17.

11. Torchinsky A, Fein A, Toder V: Teratogen-induced apoptotic cell death: does the apoptotic machinery act as a protector of embryos exposed to teratogens?. Birth Defects Res C Embryo Today 2005, 75:353-361.

12. He $X, H e ~ L$, Hannon GJ: The guardian's little helper: microRNAs in the p53 tumor suppressor network. Cancer Res 2007, 67:11099-11101.

13. Nicol CJ, Harrison ML, Laposa RR, Gimelshtein IL, Wells PG: A teratologic suppressor role for p53 in benzo[a]pyrene-treated transgenic p53-deficient mice. Nat Genet 1995, 10:181-187.

14. Wubah JA, Ibrahim MM, Gao X, Nguyen D, Pisano MM, Knudsen TB: Teratogen-induced eye defects mediated by p53-dependent apoptosis. Curr Biol 1996, 6:60-69.

15. Moallem SA, Hales BF: The role of $\mathrm{p} 53$ and cell death by apoptosis and necrosis in 4-hydroperoxycyclophosphamide-induced limb malformations. Development 1998, 125:3225-3234.

16. Pekar O, Molotski N, Savion S, Fein A, Toder V, Torchinsky A: p53 regulates cyclophosphamide teratogenesis by controlling caspases $3,8,9$ activation and NF-kappaB DNA binding. Reproduction 2007, 134:379-388.

17. Norimura T, Nomoto S, Katsuki M, Gondo Y, Kondo S: p53-dependent apoptosis suppresses radiation-induced teratogenesis. Nat Med 1996, 2:577-580
18. Wang B, Ohyama H, Haginoya K, Odaka T, Yamada T, Hayata I: Prenatal radiation-induced limb defects mediated by Trp53-dependent apoptosis in mice. Radiat Res 2000, 154:673-679.

19. Pani $L$, Horal M, Loeken MR: Rescue of neural tube defects in Pax-3deficient embryos by p53 loss of function: implications for Pax-3dependent development and tumorigenesis. Genes Dev 2002, 16:676-680.

20. Fridman JS, Lowe SW: Control of apoptosis by p53. Oncogene 2003, 22:9030-9040.

21. Pietenpol JA, Stewart ZA: Cell cycle checkpoint signaling: cell cycle arrest versus apoptosis. Toxicology 2002, 181-182:475-481.

22. Torchinsky A, Savion S, Gorivodsky M, Shepshelovich J, Zaslavsky Z, Fein A Toder V: Cyclophosphamide-induced teratogenesis in ICR mice: the role of apoptosis. Teratog Carcinog Mutagen 1995, 15:179-190.

23. Molotski N, Savion S, Gerchikov N, Fein A, Toder V, Torchinsky A: Teratogen-induced distortions in the classical NF-kappaB activation pathway: correlation with the ability of embryos to survive teratogenic stress. Toxicol Appl Pharmacol 2008, 229:197-205.

24. Faraoni I, Antonetti FR, Cardone J, Bonmassar E: miR-155 gene: a typical multifunctional microRNA. Biochim Biophys Acta 2009, 1792:497-505.

25. Teng G, Papavasiliou FN: Shhh! Silencing by microRNA-155. Philos Trans $R$ Soc Lond B Biol Sci 2009, 364:631-637.

26. Tili E, Michaille JJ, Cimino A, Costinean S, Dumitru CD, Adair B, Fabbri M, Alder H, Liu CG, Calin GA, Croce CM: Modulation of miR-155 and miRNA$125 \mathrm{~b}$ levels following lipopolysaccharide/TNF-alpha stimulation and their possible roles in regulating the response to endotoxin shock. J Immunol 2007, 179:5082-5089.

27. Baud V, Karin M: Signal transduction by tumor necrosis factor and its relatives. Trends Cell Biol 2001, 11:372-377.

28. Torchinsky A, Shepshelovich J, Orenstein H, Zaslavsky Z, Savion S, Carp H, Fain A, Toder V: TNF-alpha protects embryos exposed to developmental toxicants. Am J Reprod Immunol 2003, 49:159-168.

29. Bommer GT, Gerin I, Feng Y, Kaczorowski AJ, Kuick R, Love RE, Zhai $Y$, Giordano TJ, Qin ZS, Moore BB, MacDougald OA, Cho KR, Fearon ER: p53-mediated activation of miRNA34 candidate tumor-suppressor genes. Curr Biol 2007, 17:1298-1307.

30. He L, He X, Lim LP, de Stanchina E, Xuan Z, Liang Y, Xue W, Zender L, Magnus J, Ridzon D, Jackson AL, Linsley PS, Chen C, Lowe SW, Cleary MA, Hannon GJ: A microRNA component of the p53 tumour suppressor network. Nature 2007, 447:1130-1134.

31. Raver-Shapira N, Oren M: Tiny actors, great roles: microRNAs in p53's service. Cell Cycle 2007, 6:2656-2661.

32. Raver-Shapira N, Marciano E, Meiri E, Spector Y, Rosenfeld N, Moskovits N, Bentwich Z, Oren M: Transcriptional activation of miR-34a contributes to p53-mediated apoptosis. Mol Cell 2007, 26:731-743.

33. Christoffersen NR, Shalgi R, Frankel LB, Leucci $E$, Lees M, Klausen M, Pilpel $Y$ Nielsen FC, Oren M, Lund AH: p53-independent upregulation of miR-34a during oncogene-induced senescence represses MYC. Cell Death Differ 2010, 17:236-245.

34. Zhao JJ, Sun DG, Wang J, Liu SR, Zhang CY, Zhu MX, Ma X: Retinoic acid downregulates microRNAs to induce abnormal development of spinal cord in spina bifida rat model. Childs Nerv Syst 2008, 24:485-492.

35. Chung MK, Kim JC, Han SS: Embryotoxic effects of CKD-602, a new camptothecin anticancer agent, in rats. Reprod Toxicol 2005, 20:165-173.

36. Le MT, Teh C, Shyh-Chang N, Xie H, Zhou B, Korzh V, Lodish HF, Lim B: MicroRNA-125b is a novel negative regulator of p53. Genes Dev 2009, 23:862-876.

37. Yamakuchi M, Lowenstein CJ: MiR-34, SIRT1 and p53: the feedback loop. Cell Cycle 2009, 8:712-715.

38. Chang TC, Wentzel EA, Kent OA, Ramachandran K, Mullendore M, Lee KH, Feldmann G, Yamakuchi M, Ferlito M, Lowenstein CJ, Arking DE, Beer MA Maitra A, Mendell JT: Transactivation of miR-34a by p53 broadly influences gene expression and promotes apoptosis. Mol Cell 2007, 26:745-752.

39. Rokhlin OW, Scheinker VS, Taghiyev AF, Bumcrot D, Glover RA, Cohen MB: MicroRNA-34 mediates AR-dependent p53-induced apoptosis in prostate cancer. Cancer Biol Ther 2008, 7:1288-1296.

40. Gironella M, Seux M, Xie MJ, Cano C, Tomasini R, Gommeaux J, Garcia S, Nowak J, Yeung ML, Jeang KT, Chaix A, Fazli L, Motoo Y, Wang Q, Rocchi P, Russo A, Gleave M, Dagorn JC, lovanna JL, Carrier A, Pébusque MJ, Dusetti NJ: Tumor protein 53-induced nuclear protein 1 expression is repressed by miR-155, and its restoration inhibits pancreatic tumor development. Proc Natl Acad Sci USA 2007, 104:16170-16175. 
41. Friedman RC, Farh KK, Burge CB, Bartel DP: Most mammalian mRNAs are conserved targets of microRNAs. Genome Res 2009, 19:92-105.

42. Nielsen CB, Shomron N, Sandberg R, Hornstein E, Kitzman J, Burge CB: Determinants of targeting by endogenous and exogenous microRNAs and siRNAs. Rna 2007, 13:1894-1910.

43. Kertesz M, lovino N, Unnerstall U, Gaul U, Segal E: The role of site accessibility in microRNA target recognition. Nat Genet 2007, 39:1278-1284.

44. Xu D, Wilson TJ, Chan D, De Luca E, Zhou J, Hertzog PJ, Kola I: Ets1 is required for $\mathrm{p} 53$ transcriptional activity in UV-induced apoptosis in embryonic stem cells. Embo J 2002, 21:4081-4093.

45. Katoh Y, Katoh M: Integrative genomic analyses on GLI2: mechanism of Hedgehog priming through basal GLI2 expression, and interaction map of stem cell signaling network with P53. Int J Oncol 2008, 33:881-886.

46. Hornstein E, Shomron N: Canalization of development by microRNAs. Nat Genet 2006, 38(Suppl):S20-24

47. Stark A, Brennecke J, Bushati N, Russell RB, Cohen SM: Animal MicroRNAs confer robustness to gene expression and have a significant impact on 3'UTR evolution. Cell 2005, 123:1133-1146.

48. Li X, Cassidy JJ, Reinke CA, Fischboeck S, Carthew RW: A microRNA imparts robustness against environmental fluctuation during development. Cell 2009, 137:273-282

49. Leung AK, Sharp PA: microRNAs: a safeguard against turmoil?. Cell 2007, 130:581-585.

50. Jacks T, Remington L, Williams BO, Schmitt EM, Halachmi S, Bronson RT, Weinberg RA: Tumor spectrum analysis in p53-mutant mice. Curr Biol 1994, 4:1-7.

51. Mirkes PE: Cyclophosphamide teratogenesis: a review. Teratog Carcinog Mutagen 1985, 5:75-88

52. Manson JM, Smith CC: Influence of cyclophosphamide and 4-ketocyclophosphamide on mouse limb development. Teratology 1977, 15:291-299.

53. Hales BF, Jain R: Differential effects of 4-hydroperoxycyclophosphamide on limb development in vitro. Teratology 1986, 34:303-311.

54. Livak KJ, Schmittgen TD: Analysis of relative gene expression data using realtime quantitative PCR and the 2(-Delta Delta C(T)) Method. Methods 2001, 25:402-408.

55. Sokal RR, Rohlf FJ: Biometry: the principles and practice of statistics in biological research. New York (NY): Freeman, 31995.

56. Torchinsky A, Fein A, Toder V: Immunoteratology: I. MHC involvement in the embryo response to teratogens in mice. Am J Reprod Immunol 1995, 34:288-298.

57. Fleiss JL: Statistical methods for rates and proportions. New York: Wiley 1981

doi:10.1186/1471-213X-10-20

Cite this article as: Gueta et al.: Teratogen-induced alterations in microRNA-34, microRNA-125b and microRNA-155 expression: correlation with embryonic p53 genotype and limb phenotype. BMC Developmental Biology 2010 10:20.

\section{Submit your next manuscript to BioMed Central and take full advantage of:}

- Convenient online submission

- Thorough peer review

- No space constraints or color figure charges

- Immediate publication on acceptance

- Inclusion in PubMed, CAS, Scopus and Google Scholar

- Research which is freely available for redistribution

Submit your manuscript at www.biomedcentral.com/submit 